IFN Working Paper No. 718, 2007

\title{
On the Anticompetitive Effect of Exclusive Dealing when Entry by Merger is Possible
}

Chiara Fumagalli, Massimo Motta and

Lars Persson 


\title{
On the anticompetitive effect of exclusive dealing when entry by merger is possible*
}

\author{
Chiara Fumagalli†, Massimo Motta Lars Persson $^{\S}$
}

September 20, 2007

\begin{abstract}
We extend the literature on exclusive dealing, which assumes that entry can occur only by installing new capacity, by allowing the incumbent and the potential entrant to merge. This uncovers new effects. First, exclusive deals can be used to improve the incumbent's bargaining position in the merger negotiation. Second, the incumbent finds it easier to elicit the buyer's acceptance. Third, exclusive dealing, despite allowing the more efficient technology to find its way into the industry, reduces welfare because (i) it may trigger entry through merger whereas independent entry would be socially optimal, (ii) it leads to a sub-optimal contractual price when the exclusive dealing include a price commitment, (iii) it may deter entry altogether.
\end{abstract}

JEL Code: L24, L42.

Keywords: Technology transfer, inefficient entry, antitrust authority's behavior.

*This paper is a substantially revised version of our working paper "Exclusive Dealing, Entry and Mergers", CEPR DP No. 4902 and CSEF WP No. 153. We are very grateful to Hans Carlsson, Joe Farrell, Walter Garcia Fontes, Susana Iranzo, Doh-Shin Jeon, Chris Snyder, David Spector, Lucy White and especially to Pierre Regibeau and Patrick Rey for insightful discussions. We also thank seminar participants at European University Institute, Università di Verona, Università Bocconi, Università di Bologna, Università di Salerno, Colegi de Economia (Barcelona), Toulouse (Conference en l'honneur de Jean-Jacques Laffont), Dartmouth College, University of Zürich, Kyoto University, SNEE European integration conference in Mölle, and at 2006 Conference on Competition and Regulation (Corfu).

†Università Bocconi, European University Institute, CEPR and CSEF. Address: Istituto di Economia Politica, Via Gobbi, 520136 Milano (Italy). Tel. +39-02-58365311. Fax: +39-02-58365318. E-mail: chiara.fumagalli@unibocconi.it

‡European University Institute, Universitat Pompeu Fabra and CEPR. Address: Department of Economics, via della Piazzuola 43, I-50133, Firenze. E-mail: massimo.motta@iue.it

§IFN (The Research Institute of Industrial Economics) and CEPR. Address: Box 55665, SE-102 15 Stockholm, Sweden. Tel:+46-(0)8-665 4504, Fax: +46-(0)8-665 4599. E-mail: Lars.Persson@ifn.se 


\section{Introduction}

Exclusive dealing provisions are contracts between a buyer and a seller that prohibit the buyer from trading with other (typically rival) sellers. The possible anti-competitive effect of such contracts, which has been at the centre of several prominent antitrust cases both in the US and in Europe, ${ }^{1}$ is one of the most controversial issues in antitrust.

In the U.S., the courts treated exclusive dealing harshly for many years. The justification for this treatment was that if a buyer signs an exclusive contract, all other sellers are foreclosed from competing for that buyer's business. Hence, exclusive contracts can easily lead to exclusion of competitors and to monopolization. Beginning in the 1950s, this view was attacked by the so-called "Chicagoschool" scholars on the grounds that excluding rivals by means of exclusive contracts is not profitable for the seller. ${ }^{2}$ This view has been very influential and led U.S. courts to adopt an opposite benevolent stance towards exclusive dealing. However, beginning in the mid-1980s a number of authors have showed that the courts' traditional concern was not ill-founded and have formally established that, under specific circumstances, an incumbent firm can profitably use exclusive contracts to deter entry of a more efficient rival. See, for instance, Aghion and Bolton (1987), Spier and Whinston (1995), Rasmusen et al. (1991), Segal and Whinston (2000), Bernheim and Whinston (1998), and Fumagalli and Motta (2006). ${ }^{3}$ This triggered the U.S. courts to take the anti-competitive effects of exclusive dealing more seriously in several recent cases (such as the ones mentioned in footnote 1 above). ${ }^{4}$

A common feature of this recent literature is the assumption that the new firm can enter the market only by establishing an independent plant. Then, when the presence of the exclusive dealing forecloses access to the buyers, thereby making independent entry unprofitable, the more efficient firm is forced to stay out of the market. However, it is natural to think that a more advanced technology can find other channels to find its way into the market. A merger with the incumbent, or a licensing agreement with it, are examples of such channels. ${ }^{5}$

\footnotetext{
${ }^{1}$ Among early important decisions involving exclusive dealing arrangements, see Standard Fashion Co. v. MagraneHouston Co. [258 U.S. 346 (1922)], Standard Oil Co. of California v. U.S. [337 US 293 (1949)], and U.S. v. United Shoe Machinery Corporation [347 U.S. 521 (1954)]. Among recent cases, see Schöller v. Commission, European Court Case T-9/95, U.S. v. Microsoft (1995 Consent Decree), U.S. v. Dentsply [399 F.3d 181 (2001)], Conwood v. United States Tobacco [290 F.3d 768 (2002)] and U.S. v. Visa USA [344 F.3d 229 (2003)].

${ }^{2}$ See Director and Levi (1956), Posner (1976) and Bork (19789. For a more formal explanation of their argument see below. See also Motta (2004: 363-4) for a textbook presentation.

${ }^{3}$ Aghion and Bolton (1987) is distinct from the other papers because entry is deterred by the incumbent only "by mistake". The incumbent uses the exclusive contract, which includes a price commitment and a penalty to be paid in case the buyer switches to the entrant, to extract rents from the entrant. If the incumbent knew the costs of the entrant with certainty, it would always prefer to set the contract terms so as to allow the entrant into the industry and collect the rents created by its more efficient technology through the penalty. Under uncertainty, a penalty which is optimal ex-ante might turn out to be too high for an entrant and entry might therefore be involuntarily deterred. Spier and Whinston (1995) show that, in the presence of noncontractible relationship-specific investments, the inefficient use of stipulated damages identified by Aghion and Bolton emerges despite the buyer's and seller's ability to renegotiate the initial contract.

${ }^{4}$ Hence U.S. courts now try to assess case by case whether the anti-competitive harm exists and whether it dominates the potential efficiency-enhancing benefits. Instead in the EU, the use of exclusive dealing by a dominant firm is, by and large, prohibited per se. However, this formalistic approach is now under revision and many antitrust experts suggest to move to an "effects-based" approach also in Europe. Recent policy discussions of exclusive contracts include Whinston (2001), Jacobson (2002) and Farrell (2005).

${ }^{5}$ Another mechanism would be to allow for the exclusive dealing to be renegotiated. Like most of the literature on
} 
The beer industry provides some insightful anecdotal evidence on the relation between exclusive dealing and mergers. Establishing exclusive dealing arrangements with independent distributors is a strategy commonly adopted by incumbent firms to create strong distribution networks, which represent a relevant competitive advantage against rivals. In order to overcome such a barrier, new entrants have sometimes resorted to mergers and acquisitions. For instance, in 2003 Interbrew, a big Belgian brewer, acquired $70 \%$ of K.K. Brewery, the leading beer maker in Zhejiang Province, in China. Other Western brewers (such as Anheuser-Busch and SAB-Miller) were also using acquisitions to get into the second largest market in the world. For foreigners this push was a second attempt. During the 1990s several of them failed to break into the market: they tried to do it alone but they could not compete successfully without the access to local distribution networks. ${ }^{6}$

Another example is the development in the US beer industry in the 1990s, as described by Tremblay and Tremblay (2005), where strong incumbents strengthened their exclusivity deals with distributors in reaction to the growth of micro breweries in order to induce exit and takeovers: "...in the 1990s Anheuser-Busch and Miller started financial incentive programmes that encouraged distributors to exclusively carry their own regular and speciality brands in effort to squeeze out rival craft and contract products (...)". This induced some successful micro brewers to sell part of their shares to the incumbents. ${ }^{7}$ Indeed, according to Kurt Widmer, the founder of the Widmer brewery, "... selling a $31 \%$ share of his company to Anheuser-Busch, by providing access to their best-in-theindustry distribution system, was the only way to avoid killing the company and have the chance to expand $(\ldots) . " 8$

More generally, that incumbents' relation to customers affects the entry mode in new markets is supported by the literature on foreign direct investments which documents that multinational firms tend to enter into foreign markets via M\&As rather than greenfield investments in order to have access to strategic assets such as local distribution networks. ${ }^{9}$

Allowing the entrant to merge with the incumbent, thereby providing an alternative channel for efficient entry to take place, raises the question of whether exclusive dealing can still be used by an incumbent firm for anti-competitive purposes. In this paper we address this question, which - to the best of our knowledge - has not been studied yet. ${ }^{10}$

We construct a model where the entrant might enter the industry either via independent production or through a merger: in the latter case, the merged entity will employ the entrant's more efficient technology in the incumbent's existing plant. Note that the merger could also be interpreted as a

\footnotetext{
exclusive dealing, we rule out renegotiation (see more below for discussion).

${ }^{6}$ See The Economist, "Beer in China: Masks off, down the hatch", May 15th 2003.

${ }^{7}$ In terms of our discussion, micro brewers could be likened to an efficient entrant with superior technology (product) but no access to buyers because of exclusive contracts which link the latter with the incumbents.

${ }^{8}$ See Bizjournals "Beer brothers eye bigtime: Widmer Brothers Brewing hopes to take its brand national", 8th November 1999.

${ }^{9}$ See World Investment Report (2000) and its reference to different studies of cross-border M\&As.

${ }^{10}$ To our knowledge, the only paper that studies the interaction between mergers and exclusive contracts is Chen and Riordan (2006). However, they focus on vertical mergers and address a different issue. In particular, they consider two buyers that compete (vigorously) in a downstream market, and show that an upstream supplier which is vertically integrated with one of them is able to induce the other buyer to accept exclusivity, thereby foreclosing an equally efficient upstream rival and monopolizing the downstream market. Under vertical separation, instead, gaining compliance on exclusivity by both downstream firms would be too costly.
} 
licensing agreement or a transfer of technology: the incumbent buys the efficient technology from the entrant, which will not operate independently in the market. (Throughout the paper, we shall mostly use the term "mergers", but it should be clear that we could indifferently talk of licensing agreements.) We also introduce an Antitrust Agency which scrutinizes the merger proposal (or the licensing agreement) and only approves welfare-improving operations. ${ }^{11}$

We show that the consideration of mergers (or licensing agreements) uncovers three new effects of exclusive dealing. First, exclusive dealings help the incumbent in its bargaining over the terms of the acquisition. Under exclusivity, if the negotiation collapsed, independent entry would not be possible and the incumbent would receive its monopoly profits. Instead, absent exclusivity, if the negotiation collapsed, independent entry would occur and the incumbent would receive zero profit. Therefore, the incumbent's disagreement payoff is larger under exclusive dealing and it extracts a larger total payoff from the negotiation. In a sense, exclusive dealing facilitates the extraction of rents from the more efficient entrant, similarly to what happens in Aghion and Bolton (1987) where, however, rents are extracted through liquidated damages, i.e. penalties established in the exclusive contract to be paid in case of breach.

Albeit the mechanism is completely different, this result echoes the discussion of predation when mergers are possible. In reply to McGee (1958)'s well-known critique that it would be more profitable for the incumbent to take over the rival rather than preying upon it, Telser (1966) and Yamey (1972) argued that predation and merger might well be complementary strategies: by engaging in predatory behavior, the incumbent might induce an entrant to sell its assets at a lower price, an argument later formalized by Saloner (1987) and Persson (2004).

Second, contrary to the "Chicago School" critique, when mergers (or licensing agreements) are possible, the incumbent can profitably induce the buyer to accept exclusivity. In the standard "Chicago School" model mergers are not allowed. Then, signing the contract altogether deters entry, while independent entry occurs if the contract is rejected. It follows that the incumbent should compensate the buyer for paying the monopoly price instead of the incumbent's marginal cost (which is the price prevailing under independent entry), in order to elicit his acceptance. Due to the monopoly deadweight loss, the incumbent's gain from entry deterrence (the monopoly profits) is insufficient to profitably offer this compensation and the exclusive deal will not be signed in equilibrium. Allowing for mergers in the "Chicago school" setting makes it profitable to elicit the buyer's acceptance for two reasons. First, there are cases (depending on the entrant's marginal cost) where the merger will occur irrespective of whether the exclusive dealing has been signed: here, the buyer would require no compensation to sign exclusivity. Second, there are cases where the merger will occur only when exclusivity has been signed (independent entry occurring otherwise). In this case, inducing the buyer to sign exclusivity is facilitated by the fact that the merger makes the incumbent more efficient: on the one hand, the buyer will pay a lower price than if he had to buy from the less efficient monopolist; on the other hand, the incumbent will extract part of the merger surplus. Relative to the standard

\footnotetext{
${ }^{11}$ This is precisely what happens in the US and in Europe. Note that antitrust agencies monitor not only mergers, but also horizontal agreements (i.e., agreements between competing firms), such as licensing agreements.
} 
"Chicago-school" type model without mergers, the buyer will demand a lower compensation to sign exclusivity, and the incumbent will have higher gains from it.

Third, we show that - despite the possibility of a merger (or licensing agreement), which indeed allows the more efficient technology to find its way into the industry and makes inefficiencies in production less of a concern - exclusive dealing is still welfare-reducing. ${ }^{12}$ This occurs for three reasons. First, there are cases (depending again on the entrant's marginal cost) where exclusive deals trigger an inefficient entry mode: in equilibrium, entry occurs through a merger rather than by independent entry, which entails an allocative inefficiency since the merger removes competition and increases the market price. The intuition for this result is that the Antitrust Authority cannot but authorize the merger in the presence of exclusive deals, while it blocks the merger and implements independent entry when no exclusive contract has been signed. The reason being that in the former case the merger replaces an inefficient monopoly with a more efficient one (which is welfare beneficial), while in the latter case the merger replaces independent entry with a monopoly (which is welfare detrimental). Second, when the exclusive contract includes a price commitment, exclusive dealing leads to a sub-optimal choice of the contractual price. Finally, there are also cases where exclusive dealing altogether deters entry. This effect can arise in the case of uncertainty, where the incumbent and the buyer decide on exclusivity before knowing the actual cost of the entrant. In this case, the buyer might end up accepting ex ante an exclusive contract with a compensation that turns out to be too small ex post (that is, after the technology of the entrant is revealed). Efficient entry is deterred by "a mistake" of the buyer who asks too small a compensation, much in a similar way as in Aghion and Bolton (1987) where entry is deterred by "a mistake" of the incumbent which sets too large a penalty on breach of contract.

Our results lead to the following policy implications. First, the intensity of upstream competition matters when analyzing exclusive dealing. The fact that upstream firms can merge, thereby removing competition, enables the incumbent to elicit the buyer's acceptance, which harms welfare. In a similar vein, Farrell (2005) shows that when upstream sellers compete in quantities rather than in prices (as assumed in the Chicago school argument) the incumbent can induce to buyer to sign the exclusive contract, thereby deterring entry. The intuition is that if the buyer expects that, absent exclusivity, the entrant and the incumbent will not be fierce competitors, then he will request a small compensation for accepting the exclusive contract. Hence, weak upstream competition facilitates anti-competitive exclusive dealing.

Second, antitrust authorities should be aware that the welfare detrimental effect of exclusive dealing does not stem only from foreclosure. Indeed our analysis shows that exclusive dealing can harm welfare also through their impact on merger (or licensing) decisions. Hence, antitrust authorities should take into account that the policy concerning exclusive contracts and the policy concerning horizontal mergers (licensing agreements) are related. Differently stated, exclusive contracts and

\footnotetext{
${ }^{12}$ Naturally, this result should not be read as an implication that exclusive dealing should be banned: by construction our model does not take into account possible pro-competitive effects of exclusive contracts, which may be importanti in the real world.
} 
horizontal mergers (licensing agreements) should not be evaluated in isolation, but when assessing the anti-competitive effects of exclusive dealing, antitrust authorities should anticipate the effect that it may exert on the subsequent merger (or licensing) decisions.

The paper is organized in the following way. Section 2 describes the basic model and our main results. Section 3 discusses a number of extensions to the basic model. Section 4 concludes.

\section{The model}

We consider an incumbent firm (denoted as firm $I$ ) which supplies a good to a single buyer, incurring a constant marginal cost $c_{I} \cdot{ }^{13}$ The buyer's demand is given by $q=q(p)$.

The incumbent faces a threat of entry by a more efficient firm $E$, whose marginal cost of producing the same homogenous good is $c_{E}<c_{I}$. The entrant can choose between two modes of entry. (1) It can set up an independent firm paying a fixed sunk cost $f>0$. If independent entry occurs, the entrant and the incumbent compete à la Bertrand. To highlight the potential anti-competitive effects of an exclusive deal contract, we assume that independent entry is profitable:

$$
\left(c_{I}-c_{E}\right) q\left(c_{I}\right)-f>0
$$

which requires that the entrant is sufficiently more efficient than the incumbent, i.e. $c_{E}<c_{E}^{d}(f)$ where $c_{E}^{d}<c_{I}$ is the $c_{E}$ ensuring that $A 1$ holds as equality. (2) Alternatively, the entrant can merge with the incumbent. In this case, the firm resulting from the merger will adopt the entrant's more advanced technology. For simplicity, it is here assumed that adapting the existing plant to the entrant's technology is costless. (Section 3.2 will discuss the case of costly technology adoption.) Further, to highlight the possible anti-competitive effects of the merger, we assume that the efficiency gap between the entrant and the incumbent is not drastic:

$$
p^{m}\left(c_{E}\right) \geq c_{I}
$$

where $p^{m}(c)$ denotes the monopoly price charged by a firm with marginal cost $c$.

Firms planning to merge must notify the project to an Antitrust Agency (denoted as AA), which decides whether to authorize or block the merger. The AA's decision is taken in order to maximize total surplus, measured by the sum of consumer and producer surplus. (Section 3.3 will discuss the case where the AA's objective function is consumer surplus.)

In case of a merger, the incumbent and the entrant negotiate over the distribution of the realized surplus. We do not adopt any specific bargaining protocol. We simply assume that the involved parties agree on the merger if each player receives at least its disagreement payoff. A share $\beta \in[0,1]$ of the realized net surplus is appropriated by the incumbent ( $1-\beta$ by the entrant). For instance, if

\footnotetext{
${ }^{13}$ Considering a single buyer is not a limitation of the analysis. Indeed, when the merger option is not taken into account, assuming multiple buyers rather than a single one is crucial for the anti-competitive effect to arise. Indeed the main insight of the literature mentioned in the Introduction is that the incumbent can profitably deter entry by exploiting the externality that a buyer exerts on the others by signing the exclusive contract. Instead, when mergers are possible, the anticompetitive effect of exclusive dealings arises also with a single buyer. Considering multiple buyers would only reinforce our results.
} 


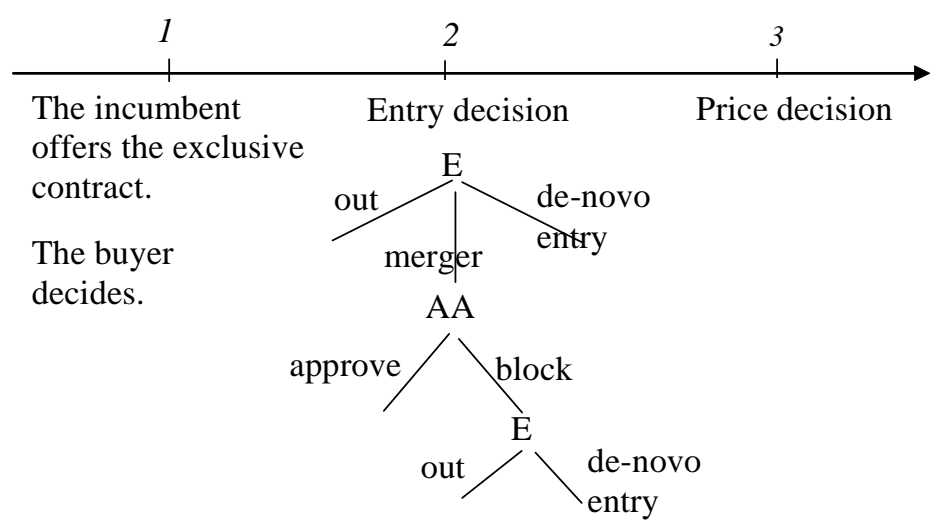

Figure 1: Time-Line.

the entrant can make take-it-or-leave-it offers to the incumbent, then $\beta=0$. If the two firms share the gain from trade equally, then $\beta=1 / 2$.

Prior to the entry decision, the incumbent offers the buyer an exclusive dealing contract. At the time of contracting, the firms' costs are common knowledge. (Section 3.1 will deal with the case where there exists uncertainty about the entrant's marginal cost.) The exclusive contract specifies a compensation $x$ that the incumbent commits to pay to the buyer if he signs the deal, but in the base model it does not include any commitment to prices. (We will analyze the case of price commitment in Section 3.4.) Moreover, we assume that the exclusivity provision cannot be breached. ${ }^{14}$

The timing of the game is as follows (see also Figure 1):

1. At date 1, the incumbent offers the buyer an exclusive dealing contract. The buyer decides whether to sign the contract.

2. At date 2 , the entry decision is taken.

3. At date 3, active firms simultaneously name prices.

Finally, in order to simplify the analysis, we impose the following restrictions. We fix the incumbent's marginal cost to be $c_{I}=1 / 2$, we adopt a linear demand function $q(p)=1-p$, and we impose and upper bound on fixed entry costs. Specifically we require $f$ to be lower than the monopoly deadweight loss:

$$
f \leq C S\left(c_{I}\right)-C S\left(p^{m}\left(c_{I}\right)\right)-\pi^{m}\left(c_{I}\right)
$$

where $C S(p)$ denotes the surplus enjoyed by the buyer if paying the price $p$ and $\pi^{m}(c)$ the monopoly profits of a firm having marginal cost $c$. Note that with linear demand and $c_{I}=1 / 2$, assumption $A 2$

\footnotetext{
${ }^{14}$ The assumption that the exclusive contract cannot be breached is adopted by most of the literature on anticompetitive exclusive dealing. Transaction and legal costs for the buyer, or the fact that renegotiating the deal would involve lengthy and uncertain court decisions (which might imply that the buyer will be left without consuming the good until the court's judgment has been made) may explain why breaching the contract is not possible. The existence of asymmetric information concerning the entrant represents an additional reason why costly renegotiation may not occur.
} 
is satisfied for any $0 \leq c_{E} \leq 1 / 2 .{ }^{15}$

We look for subgame perfect Nash equilibria and we solve the game backwards.

Product market interaction (date 3) If no entry occurred at date 2, the incumbent charges the monopoly price $p^{m}\left(c_{I}\right)$.

If independent entry occurred, date-3 prices depend on whether the buyer accepted exclusivity. If the buyer agreed to purchase only from the incumbent, the entrant cannot sell the good and the buyer pays the monopoly price $p^{m}\left(c_{I}\right)$. Instead, if the buyer did not sign the exclusive contract, competition between the entrant and the incumbent takes place. By assumption A2 in equilibrium the more efficient entrant sells the good charging the price $c_{I}$ (we get rid of equilibria supported by weakly dominated strategies).

Finally, if entry by merger occurs, the new firm monopolizes the market and supplies the buyer charging the monopoly price $p^{m}\left(c_{E}\right)$, irrespective of whether the buyer signed the exclusive contract. In other words, exclusive contracts represent an asset in the incumbent's portfolio, which is appropriated in case of a merger.

Let us analyze the entrant's decision at date 2, starting from the decision of the AA about a proposed merger project.

\subsection{Entry decision (date 2)}

At date 2, the entrant decides among the merger, independent entry and staying out of the market. In making this choice, it anticipates the decision of the AA about the merger project.

\subsubsection{Decision of the Antitrust Authority.}

The decision of the AA depends on the market outcome arising if the merger is blocked, which in turn crucially depends on whether the exclusive contract has been signed.

(i) Exclusivity has been accepted. In this case, independent entry is unprofitable since the unique buyer is constrained to purchase from the incumbent and entry costs would remain uncovered $\left(\pi_{E}=-f<0\right)$. This implies that, should the merger be prohibited, the entrant would remain out of the market, and the incumbent's monopoly would persist. Instead, if the merger is allowed, the entrant's more advanced technology is adopted and a more efficient monopolist replaces the existing one, thereby increasing both industry profits $\left(\pi^{m}\left(c_{E}\right)>\pi^{m}\left(c_{I}\right)\right)$ and consumer surplus $\left(p^{m}\left(c_{E}\right)<p^{m}\left(c_{I}\right)\right)$. Therefore, under exclusivity the merger is always allowed:

$$
\pi^{m}\left(c_{E}\right)+C S\left(p^{m}\left(c_{E}\right)\right)>\pi^{m}\left(c_{I}\right)+C S\left(p^{m}\left(c_{I}\right)\right) \quad \text { for any } c_{E}<c_{E}^{d} .
$$

\footnotetext{
${ }^{15}$ These restrictions do not sacrify generality. The specific value of $c_{I}$ allows to economize with the parameters of the model. Linear demand simplifies the algebra and facilitates the comparison between the compensation required by the buyer to agree on exclusivity and the highest offer that the incumbent is willing to make. The upper bound on entry costs simply limits the different cases that we must analyze (see footnote 16 for a clarification on this issue). In Fumagalli, Motta and Persson (2006), Appendix A, we discuss at length that the threshold levels of the entrant's marginal cost that characterize the entry pattern require very mild assumptions on the demand function to exist. Hence the effects of exclusive deals that we identify are quite robust.
} 
(ii) Exclusivity has been rejected. In this case independent entry is profitable. The buyer is not constrained by any exclusivity obligation and competition between the incumbent and the entrant takes place if the latter establishes an independent plant. Moreover, assumption $A 1$ ensures that the buyer's demand suffices to cover the entry costs. Hence, if the merger is prohibited independent entry occurs. This implies that, in evaluating the merger project, the AA must trade off the cost in terms of increased market power (the merger removes competition between the entrant and the incumbent and the new firm charges the monopoly price $\left.p^{m}\left(c_{E}\right) \geq c_{I}\right)$ with the benefit in terms of fixed costs saving (the merger involves no fixed costs). The latter dominates if the entrant is sufficiently efficient, because this limits the price increase caused by the merger. Formally, the merger is allowed if (and only if):

$$
\pi^{m}\left(c_{E}\right)+C S\left(p^{m}\left(c_{E}\right)\right)>\left(c_{I}-c_{E}\right) q\left(c_{I}\right)+C S\left(c_{I}\right)-f .
$$

Condition (1) is satisfied if (and only if) $c_{E}<c_{E}^{r}(f) \equiv 1 / 3-1 / 3 \sqrt{1-24 f}$. The threshold $c_{E}^{r}(f) \in$ $\left[0, c_{E}^{d}\right)$ for any $f$, and it is identified by the $c_{E}$ ensuring that (1) holds as equality. ${ }^{16}$

\subsubsection{Decision of the entrant}

We can now move backwards and study the entrant's decision.

It turns out that the entrant and the incumbent are always willing to merge - irrespective of exclusivity - because the merger increases industry surplus. Under exclusivity, the merger replaces an inefficient monopolist with a more efficient one; absent exclusivity, the merger removes competition and entails a saving in fixed costs. Hence, the merger occurs whenever the AA approves the proposal.

Section 2.1.1 has shown that under exclusivity the AA always endorses the merger proposal. Hence, entry by merger always occurs. Each firm's payoff is given by its disagreement point payoff plus its share of the net realized surplus:

$$
\begin{aligned}
\pi_{I}^{s} & =\pi^{m}\left(c_{I}\right)+\beta\left[\pi^{m}\left(c_{E}\right)-\pi^{m}\left(c_{I}\right)\right] \\
\pi_{E}^{s} & =(1-\beta)\left[\pi^{m}\left(c_{E}\right)-\pi^{m}\left(c_{I}\right)\right] \geq 0
\end{aligned}
$$

with $\beta \in[0,1]$. Note that the incumbent's disagreement payoff amounts to the monopoly profits, since the entrant would stay out of the market if the negotiation should break down.

By contrast, absent exclusivity the AA approves the merger if (and only if) the entrant is sufficiently efficient $\left(c_{E}<c_{E}^{r}\right)$. When this is the case, firms' payoffs are given by:

$$
\begin{aligned}
\pi_{I}^{r, m} & =\beta\left[\pi^{m}\left(c_{E}\right)-\left(\left(c_{I}-c_{E}\right) q\left(c_{I}\right)-f\right)\right] \geq 0 \\
\pi_{E}^{r, m} & =\beta\left[\left(c_{I}-c_{E}\right) q\left(c_{I}\right)-f\right]+(1-\beta) \pi^{m}\left(c_{E}\right)>0 .
\end{aligned}
$$

Note that the incumbent's disagreement payoff now amounts to zero, since independent entry would occur if the negotiation should fail.

\footnotetext{
${ }^{16}$ Condition (1) should clarify the reason why we impose an upper bound on $f$. Larger values of $f$ would imply that either the fixed costs saving is so relevant that the merger is always allowed, or that the equation identified by (1) admits two solutions, thereby leading to an additional interval over which the merger is allowed. These cases do not deliver any new insight to the analysis.
} 


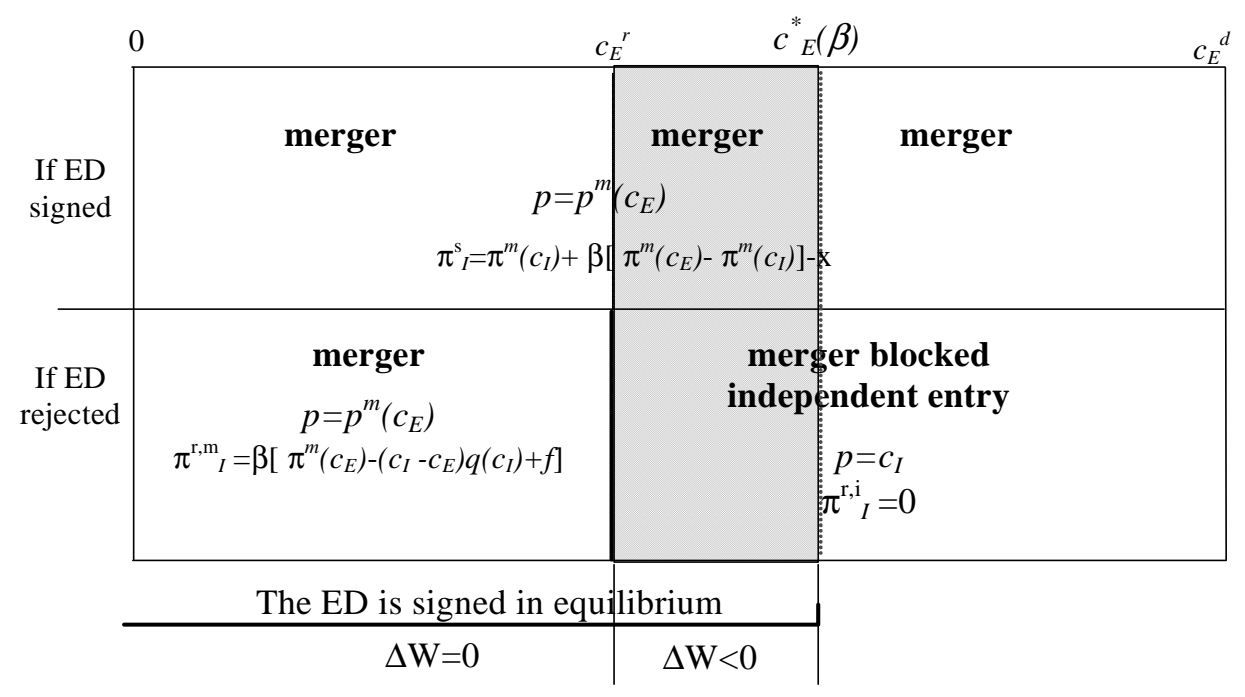

Figure 2: The entry pattern, the equilibrium choice and the welfare effects.

When instead the efficiency gap between the entrant and the incumbent is not large enough $\left(c_{E} \geq c_{E}^{r}\right)$, the merger is blocked and independent entry occurs. The incumbent's payoff is 0 while the entrant earns $\pi_{E}^{r, i}=\left(c_{I}-c_{E}\right) q\left(c_{I}\right)-f>0$.

The entry pattern is summarized by Lemma 1 and by Figure 2 .

Lemma 1 : At date 2, the entrant takes the following decision:

- If the buyer signed the exclusive deal, the entrant merges with the incumbent for any $c_{E} \in$ $\left[0, c_{E}^{d}\right)$.

- If the buyer rejected the exclusive deal, the entrant merges with the incumbent if $c_{E} \in\left[0, c_{E}^{r}\right)$. Otherwise, the merger is blocked and independent entry occurs.

Lemma 1 highlights that exclusive deals affect the entry pattern by triggering the merger instead of independent entry (when $c_{E} \in\left(c_{E}^{r}, c_{E}^{d}\right)$. The reason is that the AA is more lenient towards the merger in the presence of the exclusive agreement, since the alternative to the merger is the persistence of the former (inefficient) monopolist, whereas in the absence of exclusivity the alternative to the merger is independent entry, which is more desirable for society.

\subsection{Contracting decision (date 1 )}

We now study whether the buyer and the incumbent agree on exclusivity. We will compare the minimum compensation that the buyer requires to accept exclusivity, i.e. the one that makes him indifferent between signing and rejecting the contract, with the incumbent's gain from having the contract signed. The exclusive deal will be signed in equilibrium if the latter is larger. To do this, it proves helpful to distinguish the following two cases. 
Case 1: Large efficiency gap between the entrant and the incumbent $\left(c_{E}<c_{E}^{r}\right)$.

In this case the exclusive contract is always signed in equilibrium. The reason is that the merger occurs irrespective of exclusivity. Hence the buyer anticipates that he will end up paying the price $p^{m}\left(c_{E}\right)$ irrespective of his decision and is willing to sign the contract behind any (weakly) positive compensation $x \geq 0$. In turn the incumbent is willing to offer a strictly positive compensation to have the contract signed: by making independent entry unprofitable, having the contract signed increases its disagreement payoff and allows it to extract a larger total payoff from the negotiation for the merger. The first term on the right hand side of equation (6), which shows the maximum compensation that the incumbent is willing to offer, pinpoints this effect.

$$
\begin{aligned}
x_{I} & =\pi_{I}^{s}-\pi_{I}^{r, m}=\left[\pi^{m}\left(c_{I}\right)-0\right]+\beta\left[\left(c_{I}-c_{E}\right) q\left(c_{I}\right)-f-\pi^{m}\left(c_{I}\right)\right] \\
& =(1-\beta) \pi^{m}\left(c_{I}\right)+\beta\left(\left(c_{I}-c_{E}\right) q\left(c_{I}\right)-f\right)>0 .
\end{aligned}
$$

This analysis, by showing that exclusive deals make the incumbent a "tougher bargainer" in the subsequent merger negotiation, uncovers a new reason why exclusive deals benefit the incumbent. In a sense, the exclusive contract represents a coalition between the incumbent and the buyer at the expense of the entrant. ${ }^{17}$ This role is similar to that played by exclusive deals when the exclusivity provision can be breached by paying stipulated damages. ${ }^{18}$ In that case, the incumbent has an incentive to set the damages in such a way that (independent) entry is accommodated and that it appropriates the entire surplus the more efficient producer brings to the market.

This result echoes the discussion of predation when mergers are possible. In reply to McGee (1958)'s well-known critique that it would be more profitable for the incumbent to take over the rival rather than preying upon it, Telser (1966) and Yamey (1972) argued that predation and merger might well be complementary strategies: by engaging in predatory behavior, the incumbent might induce an entrant to sell its assets at a lower price, an argument later formalized by Saloner (1987) and Persson (2004). Similarly to these papers - although obviously with completely different mechanisms - we also find that exclusive dealing will help the incumbent in its bargaining over the terms of the acquisition.

Case 2: Small efficiency gap between the entrant and the incumbent $\left(c_{E} \geq c_{E}^{r}\right)$.

In this case, the AA approves the merger only in the presence of the exclusivity provision. Hence the buyer anticipates that he will be better off if he rejects the contract, because his rejection will cause independent entry instead of the merger and he will have pay the price $c_{I}$ instead of $p^{m}\left(c_{E}\right) \geq c_{I}$. The minimum compensation that the buyer requires to accept exclusivity is then strictly positive and amounts to surplus lost paying a larger price:

$$
x_{B}=C S\left(c_{I}\right)-C S\left(p^{m}\left(c_{E}\right)\right)>0 .
$$

By contrast the exclusive deal, by triggering the merger instead of independent entry, strictly benefits the incumbent. Under independent entry it should compete with the more efficient entrant

\footnotetext{
${ }^{17}$ The entrant's payoff would be higher if the exclusive deal were rejected: $\pi_{E}^{r, m}-\pi_{E}^{s}=\beta\left[\left(c_{I}-c_{E}\right) q\left(c_{I}\right)-f\right]+$ $(1-\beta) \pi^{m}\left(c_{I}\right)>0$.

${ }^{18}$ See Aghion and Bolton (1987) and Spier and Whinston (1995).
} 
and its payoff would be 0 , whereas when the merger occurs it obtains part of the profits generated by the new firm. Hence, the maximum compensation that the incumbent is willing to offer is given by:

$$
x_{I}=\pi_{I}^{s}-0=\pi^{m}\left(c_{I}\right)+\beta\left[\pi^{m}\left(c_{E}\right)-\pi^{m}\left(c_{I}\right)\right]>0 .
$$

Is the incumbent's benefit from having the contract signed large enough to profitably compensate the buyer? The following Lemma shows that this is the case if (and only if) the cost difference between the entrant and the incumbent is large enough.

\section{Lemma 2 Profitability of eliciting the buyer's acceptance.}

(i) For any $\beta \in[0,1]$ there exists a threshold level of the entrant's marginal cost $c_{E}^{*}(\beta) \in\left(c_{E}^{r}, c_{E}^{d}\right)$ such that $x_{I}>x_{B}$ if (and only if) $c_{E}<c_{E}^{*}(\beta)$.

(ii) The threshold $c_{E}^{*}(\beta)$ is strictly increasing in $\beta$.

Proof. See Appendix A.

The intuition for this result is that the lower $c_{E}$ the lower the monopoly price charged by the merger entity and thus the lower the loss suffered by the buyer when he signs the contract (i.e. $x_{B}$ is decreasing in $c_{E}$ ). On top of this, the lower $c_{E}$ the higher the profits generated by the merged entity and the higher the value of the merger. This makes the incumbent's benefit from having the contract signed larger (i.e. $x_{I}$ is increasing in $c_{E}$ ) since it captures a share $\beta$ of the surplus created by the merger. It follows that, when $c_{E}$ is sufficiently low, it is profitable for the incumbent to elicit the buyer's acceptance.

Moreover, note that the larger $\beta$, i.e. the larger the incumbent's share of the net realized surplus, the larger the incumbent's maximum compensation $x_{I}$. Hence, the more likely that the exclusive contract is signed in equilibrium.

Summing up the analysis, we can state the following result, which is also illustrated by Figure 2 .

Proposition 1 The equilibrium of the game exhibits the following features:

- When $c_{E} \in\left[0, c_{E}^{*}(\beta)\right)$, the exclusive contract is signed and firm $E$ enters by merging with the incumbent.

- When $c_{E} \in\left[c_{E}^{*}(\beta), c_{E}^{d}\right)$, the exclusive contract is rejected and firm E enters by establishing an independent plant.

There are two issues that are worth discussing. The first one is the role of mergers in making the exclusive deal signed. More precisely, in a setting where the possibility of mergers is not taken into account (as in the standard Chicago School setting), the exclusive contract is never signed in equilibrium. In that case having the contract signed altogether deters entry, while independent entry occurs if the contract is rejected. Hence, the incumbent should compensate the buyer for the loss suffered paying the monopoly price $p^{m}\left(c_{I}\right)$ instead of the price $c_{I}$ prevailing under (independent) entry. Due to the monopoly deadweight loss, the incumbent's gain from entry deterrence (the 
monopoly profits) is strictly lower than the buyer's loss so that the incumbent cannot profitably elicit acceptance.

Instead, when mergers are allowed for, there exist situations where the exclusive deal is signed. This occurs for two reasons. First, the fact that mergers are an entry option decreases the minimum compensation that the buyer requires to agree upon exclusivity. As the analysis above has shown, either the buyer anticipates that the merger occurs irrespective of his decision so that he will not suffer any loss when signing (i.e. $x_{B}=0$ ); or the buyer anticipates that signing triggers the merger instead of independent entry. In this case, the buyer will still pay the monopoly price instead of the competitive price $c_{I}$, but the technology transfer creates a more efficient incumbent and the buyer will pay a lower monopoly price. In other words, the buyer must be compensated for the loss caused by the price increase $p^{m}\left(c_{E}\right)-c_{I}$, which is lower than the price increase $p^{m}\left(c_{I}\right)-c_{I}$ suffered when mergers are not a feasible option. Second, the fact that mergers are an entry option increases the incumbent's benefit from the contract being signed. The reason is that, when the merger occurs, the incumbent extracts part of the net surplus realized. This reinforces the previous effect.

The second issue concerns the welfare effects of exclusive deals. In particular, exclusive deals are welfare neutral when the merger occurs irrespective of whether the exclusive deal contract is signed (i.e. when $c_{E}<c_{E}^{r}$ ). The buyer is equally well off in either case, and exclusive deals only affect the distribution of total welfare, making it more favorable for the incumbent. Instead, exclusive deals are welfare detrimental when they trigger the merger instead of independent entry (i.e. when $\left.c_{E} \in\left(c_{E}^{r}, c_{E}^{*}\right)\right)$. This follows from the fact that absent exclusivity, the AA would block the merger and would implement independent entry. Instead, in the presence of the exclusive deal contract the AA cannot but approve the merger, even though total welfare would be higher under independent entry. Consequently, we can state the following result:

Proposition 2 Banning exclusive deals would be (weakly) welfare beneficial.

Note that the detrimental effect does not stem from the fact that exclusive deals foreclose entry and prevent the adoption of the more advanced technology, but from the fact that, by distorting the AA's decision, they trigger an inefficient entry mode.

This result highlights that anti-trust authorities should be aware of the important link between the policy concerning exclusive deals and the policy concerning mergers. Differently stated, exclusive deals and mergers should not be evaluated in isolation, but when assessing the anti-competitive effects of exclusive deals, antitrust authorities should not only focus on their foreclosure potential, but should anticipate the effect that exclusive deals may exert on merger decisions.

One might wonder whether allowing for merger remedies (i.e. approving the merger subject to conditions) can help removing the inefficiency in the AA's decision. However, in the presence of the exclusive deal contract, approving the merger provided that exclusivity is breached does not implement independent entry. The only way to induce independent entry is to block the merger and dissolve exclusivity. This would not represent a merger remedy, but would be equivalent to banning exclusive deals. 
Similarly, imagine that at the beginning of the game the AA announces that it will allow mergers involving exclusive deals only if exclusivity is breached. This announcement will affect the contracting stage by reducing the incumbent's gain from having the contract signed. In particular, it is still the case that having the contract signed will trigger the merger instead of independent entry, but it will not improve the incumbent's position in the merger negotiation. Eliciting acceptance would result unprofitable. Likewise, the incumbent could not profitably induce the buyer to sign if the AA could credibly commit to block mergers that would be anti-competitive in the absence of exclusive deals. However, all these policies are equivalent to a ban on exclusive deals.

\section{Extensions}

In this Section we discuss a number of extensions to the model of Section 2.

\subsection{Uncertainty about the entrant's marginal cost.}

Section 2 assumes that when the incumbent and the buyer take their decisions on exclusivity, they can perfectly anticipate how efficient the entrant will be. This assumption may be questionable and it may seem more realistic to assume that, at the contracting stage, only the distribution function of the entrant's marginal cost is common knowledge. Appendix B solves a variant of the model where we assume that the entrant's marginal cost is uniformly distributed over the interval $[0,1]$. Most of the results obtained in the deterministic setting of Section 2 hold good. The only difference is that with uncertainty the exclusive deal contract is always signed in equilibrium as the following Proposition states:

Proposition 3 When there exists uncertainty about the entrant's marginal cost the buyer always signs the exclusive deal.

\section{Proof. See Appendix B.}

The reason is that under uncertainty, the buyer computes how much to demand as compensation by averaging over the entire range of possible realizations of the entrant's marginal costs. By so doing, he takes into account that there also exist cases where the merger occurs irrespective of his decision so that his loss from accepting exclusivity is zero. This reduces the average compensation that the buyer requires and makes it profitable for the incumbent to always elicit acceptance.

Similarly to the deterministic case, for some realizations of the entrant's marginal costs the fact that the exclusive deal is signed is irrelevant for the entry pattern, but for other realizations it will induce the AA to approve the merger even though independent entry would be socially optimal. It follows that, from an ex-ante perspective, total welfare would be higher if exclusive dealings were prohibited.

Proposition 4 Banning exclusive deals would increase total expected welfare.

Proof. See Appendix B. 


\subsection{Costly mergers.}

Section 2 assumes that mergers are costless. Let us consider now the case where adapting the incumbent's plant to the entrant's more advanced technology entails a fixed cost.

If such a cost is sufficiently low, no additional result is obtained with respect to the model of Section 2. Instead, new insights arise if the technology transfer is sufficiently costly. In particular, it turns out that exclusive deals may deter entry altogether. The intuition is that, under exclusivity, the entrant and the incumbent are not necessarily willing to merge. If their cost difference is low enough, the (small) increase of monopoly profits produced by the merger is insufficient to dominate the (large) cost associated with the technology transfer and industry surplus would decrease. ${ }^{19}$ Hence, under exclusivity the entrant stays out of the market. Instead, in the absence of exclusivity firms would like to merge, but the AA blocks the project and independent entry occurs.

However, if the entrant's marginal cost is common knowledge at the contracting stage, the incumbent would not be able to elicit the buyer's acceptance. The buyer would anticipate that his decision to sign deters entry, while independent entry occurs if he rejects. In order to sign he would require a compensation that the incumbent could not profitably offer (in other words, the Chicago school argument applies).

By contrast, the exclusive deal is signed in equilibrium if there exists uncertainty about the entrant's marginal cost. Again, uncertainty makes the buyer take into account also the realizations of the entrant's marginal cost where his loss from accepting exclusivity amounts to zero (because the merger occurs irrespective of his decision) and the ones where his decision to sign triggers the merger instead of independent entry, in which case the loss that he suffers from exclusivity is lower with respect to the case where his decision to sign leads to foreclosure. This reduces the average compensation required by the buyer and makes it profitable for the incumbent to elicit acceptance.

Note that ex-post, when the entrant's technology realizes, the compensation received may turn out to be smaller than the loss actually suffered. Hence, efficient entry ends up being deterred (or the entry mode ends up being inefficient) by "a mistake" of the buyer who asks too small a compensation, in a similar vein as in Aghion and Bolton (1987) where entry is deterred by "a mistake" of the incumbent, which sets too large a contractual penalty for breach of contract. ${ }^{20}$

\footnotetext{
${ }^{19}$ Fumagalli, Motta, Persson (2006) fully develops the case of costly mergers and identifies the exact threshold levels of the merger cost and of the entrant's marginal cost mentioned in this discussion.

${ }^{20}$ Note also that in the standard setting where mergers are not feasible, there is no scope for entry deterrence by mistake. The incumbent and the buyer anticipate that only two situations may arise. Either the realization of the entrant's marginal cost will make independent entry profitable (i.e. $c_{E}<c_{E}^{d}$ ): in this case, exclusive deals altogether deter entry; or the realization of the entrant's marginal cost will make independent entry un profitable (i.e. $c_{E} \geq c_{E}^{d}$ ). In this case, exclusive deals have no impact on the entry pattern: the incumbent's monopoly persists in either case. Hence, the incumbent benefits from having the contract signed (and the buyer suffers a loss) only in the former case. In expected terms, the maximum compensation that it is willing to offer amounts to $x_{I}^{\prime}=\pi^{m}\left(c_{I}\right) c_{E}^{d}$, while the minimun compensation required by the buyer amounts to $x_{B}^{\prime}=\left[C S\left(c_{I}\right)-C S\left(p^{m}\left(c_{I}\right)\right)\right] c_{E}^{d}$. Due to the monopoly deadweight loss, the latter is larger.
} 


\subsection{Consumer surplus as the AA's standard.}

There has been a long debate among economists on whether the objective of competition policy should be to maximize the total surplus or rather the consumer surplus, and whether, in practice, Antitrust Agencies and the Courts pursue one objective or the other. ${ }^{21}$ Therefore, it is important to note that our results do not change if we assume that the AA evaluates mergers on the grounds of consumer surplus only.

Under exclusivity the AA would always approve the merger also if it adopted a consumer surplus standard, since the merger creates a more efficient monopolist and the buyer ends up paying a lower price. Hence entry by merger would occur.

Instead, absent exclusivity the AA would always block the merger, as it cares about the increase of market power only and does not take into account that the merger entails a fixed cost saving. In this case independent entry would occur.

Thus, the difference with respect to Section 2 is that the case where the merger occurs irrespective of the exclusive deal (and the buyer signs behind a zero compensation) does not arise. But the result stated in Lemma 2 still applies, and the exclusive deal is signed in equilibrium if (and only if) the entrant is sufficiently efficient (i.e. if $c_{E}<c_{E}^{*}(\beta)$ ).

\subsection{Price commitment.}

In this Section we study the effect of exclusive deals when the contract commits the incumbent not only to offer the compensation $x$ but also to sell the good at a given price $p$.

The remaining assumptions are the same as in Section 2, except for the fact that when exclusivity has been rejected, we allow the entrant and the incumbent to use two-part tariffs. The reason is the following. Since the contract commits both to a unit price and a fixed payment, under exclusivity the incumbent is essentially using a two-part tariff, which is an instrument to eliminate inefficiencies. If we did not give the same possibility to upstream firms when exclusivity is absent, we would create a bias in favour of exclusive deals, which would turn out being welfare beneficial. However this result would be driven only by the asymmetry between the pricing strategies available to firms. ${ }^{22}$

Under two-part tariffs, the assumption that independent entry is profitable translates into

$$
C S\left(c_{E}\right)-C S\left(c_{I}\right)>f
$$

We solve the game backwards starting from the pricing decisions at date 3 .

Product market interaction (date 3) If the exclusive deal has been signed, the buyer pays the contractual price $p$ irrespective of the entry decision at date 2. In other words, in case of merger, the new firm inherits the contractual obligations undertaken by the incumbent.

\footnotetext{
${ }^{21}$ See Motta (2004: 19-22) for a discussion. See also Fridolfsson (2007), Neven and Roeller (2005) and Lyons (2002) for recent papers which provide a theoretical underpinning to a consumer surplus standard.

${ }^{22}$ In the previous draft of the paper (Fumagalli, Motta and Persson 2006), where we allowed only for linear tariffs absent exclusivity, we obtained precisely this result. We are grateful to Pierre Regibeau for bringing this point to our attention.
} 
Instead, if the exclusive deal has been rejected, date-3 prices are affected by the entry decision. If independent entry occurred at date 2 , the incumbent and the entrant compete for the buyer. The incumbent's best offer is $p_{I}=c_{I}$ and $F_{I}=0$. The entrant, being more efficient, can beat this offer by fixing the unit price equal to its (lower) marginal cost and setting the fixed fee in such a way that the buyer is indifferent between the incumbent's offer and the entrant's: $p_{E}=c_{E}$, $F_{E}=C S\left(c_{E}\right)-C S\left(c_{I}\right) .{ }^{23}$ Hence, under independent entry, the buyer enjoys a payoff equal to $C S\left(c_{I}\right)$.

If the merger occurred at date 2 , no competition takes place. The merged entity, having adopted the more advanced technology, sets also in this case a unit price equal to $c_{E}$. However, it extracts the entire consumer surplus through the fixed fee $\left(p=c_{E}, F=C S\left(c_{E}\right)\right)$, leaving the buyer with a payoff equal to 0.

Entry decision (date 2) At date 2 entry by merger occurs both if the exclusive deal has been signed and if it has been rejected. In both cases the merger increases industry surplus and the AA approves the project.

Absent exclusivity, the merger increases industry profits because it removes competition (no surplus is left to the buyer) and avoids sinking the set-up cost:

$$
C S\left(c_{E}\right)>C S\left(c_{E}\right)-C S\left(c_{I}\right)-f .
$$

Note that, due to the possibility of adopting non-linear tariffs, the merger does not entail allocative inefficiencies: both in the case of the merger and of independent entry the first-best unit price is set. Hence, the dampening of competition caused by the merger affects the distribution of total surplus but not its total amount. Since the merger produces also a fixed costs saving, it increases total surplus and the AA approves the project. ${ }^{24}$ The incumbent's and the buyer's payoff are as follows:

$$
\begin{aligned}
\pi_{I}^{r} & =\beta\left[C S\left(c_{I}\right)+f\right] \\
\pi_{B}^{r} & =0
\end{aligned}
$$

When exclusivity has been accepted, the merger increases industry surplus because the contractual quantity is produced more efficiently. More precisely, should the merger fail, the entrant would stay out of the market, the incumbent would produce the good and it would charge the contractual price $p$. In case of merger, the price must be the same, but the adoption of the more advanced technology reduces production costs:

$$
q(p)\left(p-c_{I}\right)>q(p)\left(p-c_{E}\right)
$$

Since the buyer pays the contractual price $p$ irrespective of the entry decision, also total surplus is larger when the merger occurs and the AA approves the project. The incumbent's and the buyer's

\footnotetext{
${ }^{23}$ To avoid confusion with the notation note that, absent exclusivity, the fixed component $F$ of the two-part tariff when positive - represents a payment from the buyer to the upstream firm. By contrast, under exclusivity, the fixed component $x$ - when positive - represents a payment from the incumbent to the buyer.

${ }^{24} \mathrm{Of}$ course, the decision of the AA might be different if it cared about the distribution of total surplus. For instance, the AA would block the merger if it cared about consumer surplus only.
} 
payoff are as follows:

$$
\begin{aligned}
\pi_{I}^{s} & =\left(p-c_{I}\right) q(p)+\beta\left[\left(c_{I}-c_{E}\right) q(p)\right]-x \\
\pi_{B}^{s} & =C S(p)+x .
\end{aligned}
$$

Contractual decision (date 1) The buyer anticipates that if he accepts exclusivity, he will pay the contractual price $p$ irrespective of the subsequent entry decision. Instead, if he rejects the exclusive deal, entry by merger will occur and his entire surplus will be extracted by the new monopolist. It follows that the buyer is strictly better off under exclusivity and he is willing to pay in order to sign a contract committing to the price $p$. Differently stated the minimum compensation that the buyer requires is negative, being a payment which amounts to the surplus that the buyer enjoys from paying the price $p$ rather than being extracted all the surplus:

$$
x_{B}(p)=-C S(p) .
$$

It is now possible to identify the optimal contract that the incumbent can offer in order to induce acceptance. Proposition 5 illustrates also the equilibrium of the game.

Proposition 5 The optimal contract commits to supply the good at the price $p^{*}=c_{I}-\beta\left(c_{I}-c_{E}\right)$ and to offer the compensation $x^{*}=-C S\left(p^{*}\right)<0$.

In equilibrium the incumbent offers this contract and the buyer accepts exclusivity.

Proof. By (8), the optimal contract to elicit the buyer's acceptance solves the following problem:

$$
\max _{p}\left\{\left[p-\left(c_{I}-\beta\left(c_{I}-c_{E}\right)\right)\right] q(p)+C S(p)\right\} .
$$

Recalling that $C S(p)=\int_{p}^{\infty} q(t) d t$, the first-order condition is:

$$
\left[p-\left(c_{I}-\beta\left(c_{I}-c_{E}\right)\right)\right] \frac{d q(p)}{d p}=0,
$$

and $p^{*}=c_{I}-\beta\left(c_{I}-c_{E}\right)$.

Hence by offering this contract the incumbent earns $\pi_{I}^{* s}=-x_{B}\left(p^{*}\right)=C S\left(p^{*}\right)$. Appendix C shows that $\pi_{I}^{* s}>\pi_{I}^{r}$ so that it is profitable for the incumbent to induce acceptance.

The intuition for this result is the following. When the contract is signed, the merger occurs and the incumbent earns its disagreement payoff - i.e. the profits $\left(p-c_{I}\right) q(p)$ that it would make producing and selling itself the good - plus a share of the efficiency gains that the entrant brings into the market, $\beta\left(c_{I}-c_{E}\right) q(p)$. The overall payoff, which is the first component in expression (9), can be interpreted as the profits made by a firm whose marginal cost is $c_{I}-\beta\left(c_{I}-c_{E}\right)$. On top of this, the non-linear pricing schedule (price commitment + fixed compensation) allows the incumbent to extract the buyer's surplus (second component in expression 9). As a result, the optimal contractual 
price is chosen in order to maximize the sum of the consumer and the producer's surplus, which leads to the "corrected" marginal cost pricing $p^{*}=c_{I}-\beta\left(c_{I}-c_{E}\right) .{ }^{25}$

Note that, except for the special case where $\beta=1$, the optimal contractual price $p^{*}$ is larger than the first-best price $c_{E}$ established by the merged entity absent exclusivity. Hence, unless the incumbent extracts the entire surplus generated by the merger, exclusive deals are welfare detrimental.

Proposition 6 Banning exclusive deals would be (weakly) welfare beneficial.

Again, the negative impact on welfare does not stem from foreclosure. Indeed, entry by merger occurs irrespective of the exclusive agreement. None the less total welfare is lower under exclusivity because, in that case, it is the incumbent rather than the merged entity that chooses the price. Since the incumbent appropriates only partially the efficiency gains associated with the more advanced technology, it has inadequate incentives to choose the welfare-maximizing price.

Also in this case, it is worth comparing our results with the benchmark case where mergers are not an entry option. In that case, if the buyer rejects exclusivity, independent entry occurs and competition between the entrant and the incumbent takes place. Eventually, the entrant supplies the buyer who enjoys the surplus $C S\left(c_{I}\right)$. Instead, if the exclusive deal is signed, entry does not occur and the incumbent supplies the good charging the contractual price $p$. Hence, the minimum compensation that the buyer requires to accept exclusivity amounts to $x_{B}^{\prime}=C S\left(c_{I}\right)-C S(p)$ and the incumbent's payoff from having the contract signed is given by:

$$
\pi_{I}^{s}=\left(p-c_{I}\right) q(p)+C S(p)-C S\left(c_{I}\right)
$$

It follows that the optimal contract to elicit acceptance exhibits $p^{*}=c_{I}$ and $x^{*}=0$, and that it is not profitable for the incumbent to offer it $\left(\pi_{I}^{* s}=0=\pi_{I}^{r}\right)$. In other words, exclusivity does not benefit the incumbent.

Why allowing for mergers creates the scope for eliciting acceptance in a profitable way? Again, the main reason is that, when mergers are an entry option, the buyer requires a lower compensation to agree on exclusivity:

$$
x_{B}=-C S(p)<C S\left(c_{I}\right)-C S(p)=x_{B}^{\prime} .
$$

Indeed, the buyer is willing to pay in order to sign the exclusive contract because he anticipates that, if he rejects, the merger will follow, competition will not take place, and his entire surplus will be extracted. On top of this, the fact that the incumbent appropriates part of the efficiency gains generated by the merger creates the incentive to fix a contractual price below $c_{I}$, which increases further the payment that the buyer is willing to offer and enhances the profitability of eliciting acceptance.

\footnotetext{
${ }^{25}$ We would obtain the same results under the assumption that the AA adopts a consumer surplus standard. In such a case, the merger is always blocked absent exclusivity, and it is always allowed in the presence of exclusivity (the buyer pays the contractual price irrespective of the entry decision). The compensation required by the buyer is now $C S(c)-C S(p)$, because the buyer anticipates that his rejection triggers independent entry, but the optimal contractual price is again $p^{*}$. Hence eliciting acceptance makes the incumbent earn $\pi_{I}^{s *}=C S\left(p^{*}\right)-C S\left(c_{I}\right)>0$ for any $\beta>0$. Since under independent entry the incumbent's payoff is 0 , offering the exclusive contract is profitable.
} 


\section{Conclusion}

This paper extends the existing literature on exclusive dealing by not only allowing a more efficient producer to enter the market by setting up a new venture but also by merging with the incumbent firm (or, equivalently, by licensing its more efficient technology to the incumbent).

First, we identify a new rationale for exclusive dealing provisions: they allow the incumbent to extract a larger surplus in the subsequent merger with the potential entrant. Consequently, a prediction of this paper is that, ceteris paribus, firms which lock a considerable proportion of buyers by using exclusivity provisions would gain more in merger deals (or, under the alternative interpretation, pay less in technology transfer agreements).

Second, we show that relative to the standard "Chicago-School" type model without mergers, the buyer will demand a lower compensation to sign exclusivity, and the incumbent will have higher gains from it. Hence, contrary to the "Chicago School" critique, the incumbent can profitably elicit the buyer' acceptance when mergers are possible.

Third, we show that exclusive deals are welfare detrimental - despite the existence of the merger option, which allows the more efficient technology to find its way into the industry. The reason is the following. When the contract does not include a price commitment, the presence of exclusive deals may distort the AA's decision so that in equilibrium the merger will be approved, even though total welfare would be higher under independent entry. On top of this exclusive deals might in some circumstances deter entry altogether. When the contract includes a commitment to prices, the presence of exclusive deals leads to a distortion in the choice of the contractual price.

This paper deals with exclusive contracts, but we suspect that similar effects would arise when an incumbent firm takes other actions aimed at making captive consumers, so as to make it more difficult for them to switch to new entrants. Examples of such actions could be decisions to make a product/network incompatible with other products/networks; strategies which increase artificially switching costs of consumers, and non-compete clauses in managerial contracts. 


\section{A Appendix}

The threshold $c_{E}^{*}(\beta)$ is the value of $c_{E}$ that solves the following equation:

$$
\pi^{m}\left(c_{I}\right)+\beta\left[\pi^{m}\left(c_{E}\right)-\pi^{m}\left(c_{I}\right)\right]=C S\left(c_{I}\right)-C S\left(p^{m}\left(c_{E}\right)\right)
$$

By linear demand and $c_{I}=1 / 2$, equation (10) boils down to:

$$
\frac{1}{16}+\beta\left[\frac{\left(1-c_{E}\right)^{2}}{4}-\frac{1}{16}\right]=\frac{1}{8}-\frac{\left(1-c_{E}\right)^{2}}{8}
$$

which has the (admissible) solution

$$
c_{E}=1-\frac{\sqrt{2+6 \beta+4 \beta^{2}}}{2+4 \beta} \equiv c_{E}^{*}(\beta) .
$$

Recall that $c_{E}^{r}(f)=\frac{1}{3}-\frac{1}{3} \sqrt{1-24 f}$ and $c_{E}^{d}(f)=1 / 2-2 f$. Moreover, recall that assumption (A3) requires $f \leq 1 / 32$. Simple algebra shows that $c_{E}^{*}(0)>c_{E}^{r}\left(\frac{1}{32}\right)$. Since $c_{E}^{*}(\beta)$ is increasing in $\beta$ and $c_{E}^{r}(f)$ is increasing in $f$, it follows that $c_{E}^{*}(\beta)>c_{E}^{r}(f)$ for any $\beta \in[0,1]$ and for any $f \leq 1 / 32$.

Simple algebra also shows that $c_{E}^{*}(1)<c_{E}^{d}\left(\frac{1}{32}\right)$. Since $c_{E}^{*}(\beta)$ is increasing in $\beta$ and $c_{E}^{d}(f)$ is decreasing in $f$, it follows that $c_{E}^{*}(\beta)<c_{E}^{d}(f)$ for any $\beta \in[0,1]$ and for any $f \leq 1 / 32$.

\section{B Appendix}

This Appendix assumes that at the contracting stage the incumbent and the buyer cannot perfectly anticipate the entrant's marginal cost. They just know its distribution function. After they decide on the exclusive dealing, Nature chooses the realization of the entrant's marginal cost, which becomes common knowledge. Then the entry decision and the price decisions are taken. For simplicity, we assume that the entrant's marginal cost is uniformly distributed over $[0,1]$.

The entry pattern at date 2 is summarized by Figure 3. When independent entry is profitable, Lemma 1 applies. When independent entry is not profitable (i.e. $c_{E} \geq c_{E}^{d}$ ) the alternative to the merger is "no entry" irrespective of whether the exclusive deal is signed. Hence, the decision on exclusivity does not affect the entry pattern: as long as the entrant is more efficient than the incumbent $\left(c_{E} \in\left[c_{E}^{d}, 1 / 2\right)\right)$ entry by merger occurs both with and without exclusivity; if instead the entrant is less efficient than the incumbent $\left(c_{E} \geq 1 / 2\right)$, there exists no scope for the merger and no entry occurs in both cases. For this reason the buyer is indifferent between accepting and rejecting the contract (he ends up paying the same price) and the incumbent does not gain from having the contract signed.

At date 1 the buyer computes the expected compensation required to accept exclusivity, which is given by:

$$
x_{B}=\int_{c_{E}^{r}}^{c_{E}^{d}}\left[C S\left(c_{I}\right)-C S\left(p^{m}\left(c_{E}\right)\right)\right] d c_{E}>0
$$

In turn, the incumbent computes the expected gain from eliciting acceptance:

$$
\begin{aligned}
x_{I}= & \int_{0}^{c_{E}^{r}}\left\{\pi^{m}\left(c_{I}\right)+\beta\left[-\pi^{m}\left(c_{I}\right)+\left(c_{I}-c_{E}\right) q\left(c_{I}\right)-f\right]\right\} d c_{E}+ \\
& +\int_{c_{E}^{c}}^{c^{d}}\left\{\pi^{m}\left(c_{I}\right)+\beta\left[\pi^{m}\left(c_{E}\right)-\pi^{m}\left(c_{I}\right)\right]\right\} d c_{E}>0
\end{aligned}
$$




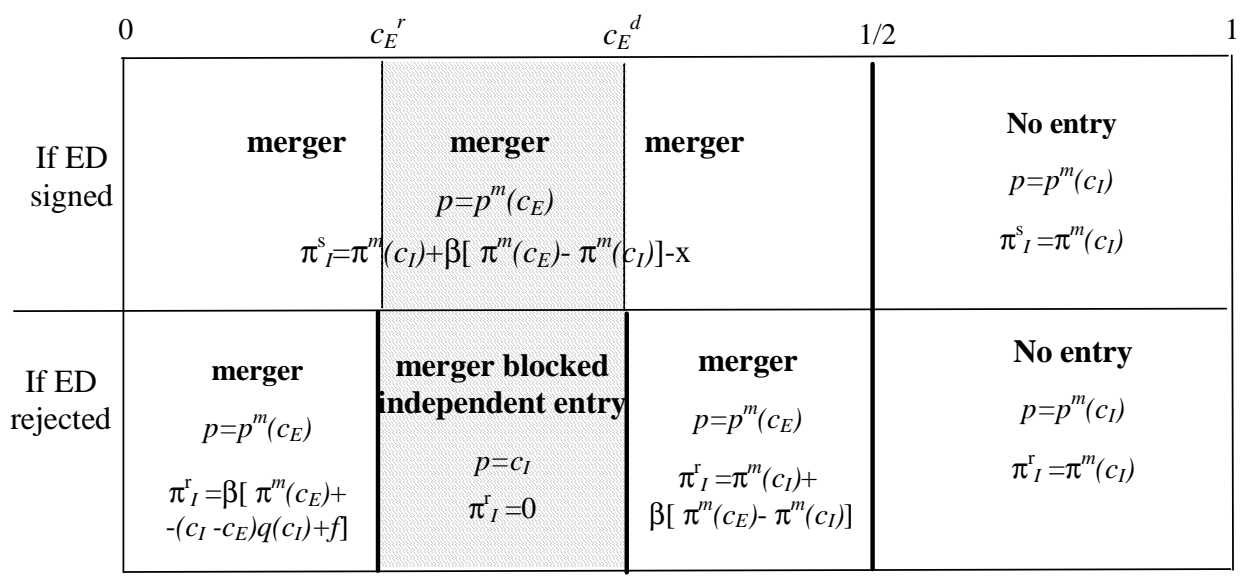

Figure 3: Entry pattern when the realization of $c_{E}$ belongs to $[0,1]$.

We now show that $x_{I}>x_{B}$ for any $\beta \in[0,1]$ so that it is profitable for the incumbent to have the contract signed.

\section{Proof of Proposition 3.}

First, let us consider the case where $\beta=0$ and $x_{I}=\pi^{m}\left(c_{I}\right) c_{E}^{d}=\frac{1}{16}\left(\frac{1}{2}-2 f\right)$. It is easy to verify that

$$
x_{I}-x_{B}=\frac{1}{16}\left(\frac{1}{2}-2 f\right)-\frac{1}{8} \int_{\frac{1}{3}-\frac{1}{3} \sqrt{1-24 f}}^{\frac{1}{2}-2 f}\left(2 c_{E}-c_{E}^{2}\right) d c_{E}>0
$$

for any $f \leq 1 / 32$.

We now show that $x_{I}$ is increasing in $\beta$. Note that when independent entry is profitable and the merger occurs anyway (i.e. when $c_{E}<c_{E}^{r}$ ), the value of the merger is different depending on whether the exclusive deal is signed or it is rejected. In particular, if the contract is signed, the merger creates a more efficient monopoly whereas if the contract is rejected, the merger creates a monopoly instead of an efficient duopolist. The increase in industry surplus can be either smaller or larger in the latter case, depending on the cost difference between the incumbent and the entrant and the cost of entry. However, in this model it turns out that for $c_{E}<c_{E}^{r}$ the duopolistic market is more profitable than the inefficient monopoly and the merger creates a larger surplus when the exclusive deal is signed. Hence, the sign of the squared bracket in the first integral of (11) is positive and the incumbent's benefit from the contract being signed increases with $\beta$. The incumbent's benefit from the contract being signed is increasing in $\beta$ also when exclusive deals make the merger occur instead of independent entry (i.e. when $c_{E} \in\left[c_{E}^{r}, c_{E}^{d}\right)$ ), since the incumbent's payoff is nil if the contract is rejected.

As a result, $\frac{\partial x_{I}(\beta)}{\partial \beta}>0$. Since $x_{B}$ does not depend on $\beta$, it must be that $x_{I}>x_{B}$ for any $\beta \in[0,1]$.

Let us analyze now the welfare effects. When the exclusive dealing does not change the entry pattern (i.e. either when $c_{E}<c_{E}^{r}$ or $c_{E} \geq c_{E}^{d}$ ), it has no effect on total welfare (recall that when the 
merger occurs irrespective of exclusivity it is the distribution of total welfare which is affected). It is only when the exclusive dealing triggers the merger instead of independent entry that total welfare is reduced, since the socially optimal entry mode entails the set up of an independent plant. Hence, banning exclusive deals would strictly increase total expected welfare, as showed by Proposition 4 .

\section{Proof of Proposition 4}

Forbidding exclusive deals causes the following expected welfare change (where $W^{i}$ with $i=f, a$ denotes total welfare when exclusive deals are, respectively, forbidden and allowed) :

$$
E\left[W^{f}\right]-E\left[W^{a}\right]=\begin{aligned}
& \int_{c_{E}^{r}}^{c_{E}^{d}}\left[C S\left(c_{I}\right)+\left(c_{I}-c_{E}\right) q\left(c_{I}\right)-f\right] d c_{E}+ \\
& -\int_{c_{E}^{r}}^{c_{E}^{d}}\left[C S\left(p^{m}\left(c_{E}\right)\right)+\pi^{m}\left(c_{E}\right)\right] d c_{E}>0
\end{aligned}
$$

by the definition of $c_{E}^{r}$.

\section{Appendix}

This Appendix shows that under price commitment eliciting acceptance is profitable for the incumbent, i.e. that

$$
\pi_{I}^{* s}=C S\left[c_{I}-\beta\left(c_{I}-c_{E}\right)\right]>\beta\left[C S\left(c_{I}\right)+f\right]=\pi_{I}^{r}
$$

for any $\beta \in[0,1]$. By assumption $A 1^{\prime}, f<C S\left(c_{E}\right)-C S\left(c_{I}\right)$. Hence, a sufficient condition for the above inequality to be satisfied is that

$$
C S\left[c_{I}-\beta\left(c_{I}-c_{E}\right)\right] \geq \beta C S\left(c_{E}\right) .
$$

When $\beta=0$, condition (12) boils down to

$$
C S\left(c_{I}\right) \geq 0
$$

which is satisfied. When $\beta=1$, condition (12) boils down to

$$
C S\left(c_{E}\right) \geq C S\left(c_{E}\right)
$$

which is satisfied.

With linear demand $C S(p)=(1-p)^{2} / 2$ and condition (12) can be written as

$$
(1-\beta)\left[\left(1-c_{I}\right)^{2}-\beta\left(c_{I}-c_{E}\right)^{2}\right] \geq 0 .
$$

By assumption $A 2,\left(1+c_{E}\right) / 2 \geq c_{I}$, which is equivalent to $c_{I}-c_{E}<1-c_{I}$. It follows that condition (12) is satisfied also when $\beta \in(0,1)$. 


\section{References}

[1] Aghion P. and Bolton P. (1987), "Contracts as a Barrier to Entry", American Economic Review, June, 77(3), 388-401.

[2] Bernheim B. D. and M. D. Whinston (1998), "Exclusive Dealing", The Journal of Political Economy, 106(1), 64-103.

[3] Bork, R. (1978), The Antitrust Paradox. New York: Basic Books.

[4] Chen Y. and M. H. Riordan (2006), "Vertical Integration, Exclusive Dealing, and Ex Post Cartelization", mimeo.

[5] Director, A. and E. Levi (1956), "Law and the future: Trade regulation", North Western University Law Review, 51: 281-296.

[6] Farrell, J., (2005), "Deconstructing Chicago on Exclusive Dealing," The Antitrust Bulletin, 50(3): 465-80.

[7] Fridolfsson, S-0 (2007), "A Consumer Surplus Defence in Merger Control", in The Political Economy of Antitrust, Vivek Ghosal and Johan Stennek (Eds.), North-Holland, forthcoming.

[8] Fumagalli, C. and M. Motta (2006), "Exclusive Dealing and Entry when Buyers Compete", American Economic Review, June.

[9] Fumagalli, C, M. Motta and L. Persson (2006), "Exclusive Dealing, Entry and Mergers", CSEF Working Paper No. 153, January.

[10] Jacobson, J. M. (2002), "Exclusive dealing, "foreclosure", and consumer harm," Antitrust Law Journal, No. 2, 311-369.

[11] Lyons, B. (2002), "Could politicians be more right than economists? A theory of merger standards", CCR Working Paper 02-1, May.

[12] McGee, J. (1958), "Predatory Price Cutting: The Standard Oil (NJ) Case", Journal of Law and Economics. 1: 137-69.

[13] Motta, M. (2004), Competition Policy. Theory and Practice, Cambridge, UK: Cambridge University Press.

[14] Neven D. and L. H. Röller (2005), "Consumer Surplus vs. Welfare Standard in a Political Economy Model of Merger Control", International Journal of Industrial Organization, Vol. 23, pp. 829-848.

[15] Persson, L. (2004), "Predation and Mergers: Is Merger Law Counterproductive?", European Economic Review, 48(2), 239-258. 
[16] Posner, R.A. (1976), Antitrust Law: An Economic Perspective. Chicago: University of Chicago Press.

[17] Rasmusen E.B., Ramseyer J. M. and Wiley J. J. S. (1991), "Naked Exclusion", American Economic Review, December, 81(5), 1137-45.

[18] Telser, L. G. (1966), "Cutthroat Competition and the Long Purse", Journal of Law and Economics. 9: 259-77.

[19] Segal I. and Whinston M.D. (2000), "Naked Exclusion: Comment", American Economic Review, 90(1), 296-309.

[20] Spier, K. E. and M. D. Whinston (1995), "On the efficiency of privately stipulated damages for breach of contract: entry barriers, reliance, and renegotiation", RAND Journal of Economics, 26(2), 180-202.

[21] Tremblay V. J. and C. H. Tremblay (2005), The U.S. Brewing Industry: Data and Economic Analysis, Cambridge, Massachusetts: The MIT Press.

[22] Whinston, M.D. (2001), "Exclusivity and Tying in U.S. v. Microsoft: What We Know, and Don't Know", Journal of Economic Perspectives, 15(2), 63-80.

[23] World Investment Report (2000), Cross Border M\&A and Development, UNCTAD.

[24] Yamey, B. (1972), "Predatory Price Cutting: Notes and Comments." Journal of Law and Economics. 15: 129-42. 